\title{
APLICAÇÃO DE UM MODELO DE CORTE DE ESTOQUE UNIDIMENSIONAL NO PLANEJAMENTO DE NECESSIDADE DE MATERIAIS ${ }^{1}$
}

\author{
Frederico Montefeltro ${ }^{a}$, Flávio Molina ${ }^{a^{*}}$ \\ ${ }^{a}$ Instituto de Ciências Exatas e Tecnológicas, Departamento de Engenharia de Produção \\ Universidade Federal do Triângulo Mineiro, Uberaba-MG, Brasil.
}

Recebido 07/08/2018, aceito 29/11/2019

\begin{abstract}
RESUMO
Os fornecedores de peças para montadoras de máquinas agrícolas têm uma alta diversidade de itens para produção. Em um dos fornecedores do interior de São Paulo, semanalmente, são recebidas ordens de fabricação de barras de corte com diferentes comprimentos. O problema tratado neste trabalho surge da necessidade de dimensionar adequadamente o estoque anual de barra chata (matéria-prima) de tal modo a evitar desperdícios. Para a resolução do problema é necessário fazer a previsão de vendas anual dos produtos que utilizam a barra chata. Tais previsões servem de entrada para calcular as necessidades dos insumos para a produção. Para agregar a demanda da matéria-prima é aplicado um problema de corte unidimensional com o objetivo de diminuir o desperdício da barra chata, que é o principal componente da barra de corte. Com isso, foi obtida uma redução nos custos da montagem das barras de corte e um menor valor de matéria-prima em estoque.
\end{abstract}

Palavras-chave: Problema de corte de estoque unidimensional, MRP, Previsão de demanda.

\begin{abstract}
Suppliers of agricultural machinery pieces have a high diversity of items for production. In one of the suppliers in the interior of São Paulo, weekly orders of production of cut bars with different lengths are received. The problem dealt with in this work arises from the need to adequately size the annual flat bar stock (raw material) to avoid waste. To solve the problem it is necessary to forecast the annual sales of products in which the flat bars are used. These forecasts serve as an input to work out the raw material for production. To aggregate the raw material demand, a one-dimensional cutting problem is applied in order to reduce the waste of the flat bar, which is the main component of the cutting bar. This resulted in a reduction in assembly costs of the cutting bars and also the value of raw material in stock.
\end{abstract}

Keywords: One-dimensional stock cutting problem, MRP, Demand prediction.

*Autor para correspondência. E-mail: flavio.silva@uftm.edu.br.

DOI: $10.4322 /$ PODes.2019.007

${ }^{1}$ Todos os autores assumem a responsabilidade pelo conteúdo do artigo. 


\section{Introdução}

A cada dia, surgem novas indústrias no mercado, bem como a fusão de uma ou mais indústrias. Em virtude desse movimento, os níveis de competitividade estão cada vez maiores, com isso há uma constante busca pela necessidade de melhoria dos processos internos e externos da empresa com o objetivo de reduzir os custos de produção e atender os seus clientes de forma eficiente. Em um aspecto geral, cada avanço contribui para uma progressão rumo a um aperfeiçoamento global (Kamimura et al., 2012).

Uma das dificuldades da maioria das empresas é uma boa gestão de estoque, em especial da matéria-prima, pois é a partir dela que os produtos são criados e vendidos. Este problema deve ser tratado dentro da empresa de modo que o volume de insumos seja muito bem dimensionado. A gestão de estoque mostra-se necessária, pois se não há uma quantidade suficiente de matéria-prima, não é possível que se consiga atender a demanda de itens a serem produzidos em um determinado período. Em contrapartida, um grande volume deste material parado em estoque faz com que haja uma quantidade de dinheiro parado em estoque, o que também não é interessante para a empresa.

Segundo Corrêa e Corrêa (2012) gestão de estoques é um componente gerencial importante para a administração atual e, também, do futuro. O uso incorreto de técnicas e conceitos de gestão de estoque acarreta excesso de itens indesejáveis com necessidade de outros itens em que se tem falta ao mesmo tempo.

O MRP (Material Requirement Planning), ou planejamento de necessidades de materiais, é uma ferramenta que pode ser de grande valia no auxílio da gestão de estoques, pois ela gera uma programação da necessidade dos componentes de cada produto, fazendo com que as quantidades a serem compradas para a fabricação sejam corretas. Fazendo a Lista de Materiais (Bill Of Materials) dos componentes dos produtos estudados e os tempos de ciclo (lead times) de cada um deles, pode-se calcular o quanto de cada matéria-prima será necessário para a montagem do produto final, de forma que não falte e nem haja sobra nos suprimentos das necessidades de produção. Este método surgiu, de acordo com Martins e Larugeni (2005), da necessidade de se planejar o atendimento da demanda dependente, isto é, aquela que está relacionada com a demanda independente. Entende-se como demanda dependente os itens tais que o consumo pode ser programado internamente, em outras palavras, são usados na produção interna de outros itens ou produtos finais. A demanda independente decorre das necessidades do mercado e se refere basicamente aos produtos acabados, ou seja, àqueles que são definitivamente entregues ao consumidor.

Para que se tenha uma boa assertividade dessa demanda independente que é decorrente da matéria-prima (demanda dependente) é necessário que se faça uma boa previsão dos produtos finais que serão vendidos. As decisões futuras relacionadas as vendas dos produtos finais geralmente são realizadas a partir de modelos de previsões de vendas.

A capacidade de prever a demanda é fundamental para toda a atividade de uma organização, pois disponibiliza as entradas para planejamento e controle de todas as áreas funcionais, incluindo logística, marketing, produção e finanças (Ballou, 2001). Nesta literatura, encontra-se diversos métodos que podem auxiliar nessa previsão de demanda da empresa. Os métodos de previsão de demanda são classificados, basicamente, em duas categorias: métodos quantitativos e qualitativos.

Alguns métodos quantitativos podem ser citados dentro dessa literatura. O método de previsão da Média Móvel é de grande utilização dentro das empresas devido a sua facilidade de aplicação. Este método não tem necessidade de muitos dados históricos, sendo indicado para previsões curtas e sem a presença de tendência e sazonalidade. Outro método bastante utilizado é a Suavização Exponencial. A Suavização Exponencial também é um método fácil utilização e possui capacidade para ser ajustado em função dos resultados obtidos.

O método de Holt-Winters (HW) é um método de série temporal que envolve equações baseadas em parâmetros de suavização exponencial que são associados a nível, tendência e sazonalidade, respectivamente. 
Em algumas empresas, mesmo com uma boa previsão da demanda de vendas dos produtos finais, o planejamento de necessidade de materiais (MRP) irá fornecer a quantidade exata de cada material utilizado na produção. Essa quantidade, em alguns casos, não necessariamente equivale ao tamanho do lote de compra, uma vez que há perdas relacionadas ao processo produtivo ou especificidades do fornecimento da matéria prima. Desse modo, se faz necessário obter ou estimar essa perda para dimensionar melhor o tamanho do lote de compra. Esse problema é encontrado em uma indústria de implemento e peças agrícolas, lotada na cidade de Ribeirão Preto, em que barras de aço trefilado são compradas em tamanhos prédeterminados, que serão cortadas pela empresa, dependendo da necessidade da produção.

Nesse trabalho é proposta, em conjunto a empresa, uma ferramenta de apoio a decisão para determinar o lote de compra das barras de aço trefilado. A ferramenta é baseada na ideia do sistema MRP, tendo como informações da produção a previsão de vendas dos produtos da empresa. Para obter uma estimativa da perda das barras de aço, que ocorre no sistema de produção, foi acoplado ao cálculo do tamanho do lote, um modelo de corte de estoque unidimensional.

Para apresentar a ferramenta de decisão proposta, o artigo está organizado do seguinte modo: na Seção 2, são apresentados os principais conceitos de Planejamento da Produção e Pesquisa Operacional utilizados no desenvolvimento da ferramenta de apoio a decisão do processo de compras. Dentre esses conceitos cabe ressaltar os métodos de previsão de demanda, em especial ao método de Holt-Winters. Além dos métodos de previsão, são apresentados também parte do conceito de MRP e o modelo matemático de corte de estoque unidimensional. $\mathrm{Na}$ Seção 3, está descrita a metodologia utilizada no desenvolvimento do trabalho. Na Seção 4, são fornecidos detalhes da empresa estudada e os resultados obtidos com a aplicação dos conceitos descritos na segunda seção. A conclusão e as considerações finais são discutidas na Seção 5 .

\section{Revisão de Literatura}

Esta seção está estruturada de acordo com cada etapa aplicada na ferramenta proposta. Desse modo, é tratado, inicialmente, os métodos de previsão de vendas existentes e justificadas as escolhas dos métodos utilizados pelos autores e empresa. Em seguida é apresentado o cálculo de necessidades de materiais utilizado no MRP. Como esse cálculo está bem consolidado na literatura, ele será apresentado de forma resumida. Por fim, é apresentado o modelo de corte de estoque unidimensional utilizado para obter a perda do processo produtivo e, desse modo, melhor dimensionar o lote de compra.

\subsection{Previsão de Vendas}

Realizar previsão de demanda é uma atividade importante para empresas, pois pode revelar as tendências de mercado e contribuir para o posicionamento estratégico da empresa. $\mathrm{Na}$ literatura podem ser encontradas diversas técnicas de previsão de demanda. Em geral, pode ser afirmado que as técnicas de previsão de demanda podem ser classificadas em "qualitativas" e "quantitativas" (Moreira, 2009). Alguns exemplos qualitativos podem ser listados: Método Ingênuo, Método Delphi, baseado na opinião dos especialistas, etc.; bem como outros quantitativos: Média Móvel, Amortização Exponencial, Amortecimento Exponencial, etc. (Davis et al., 2001).

Em empresas de pequeno porte em que há poucos funcionários e que a demanda dos últimos anos se apresentou de forma mais estável, não variando ao longo dos anos, o método Ingênuo de previsão é o mais utilizado. Este método consiste em considerar o histórico de vendas para que se possa ter uma previsão futura, acreditando que o comportamento do mercado não se modifica e se repetirá (Samohyl et al., 2008).

Outro método qualitativo também utilizado nas empresas é o baseado na opinião dos especialistas, que são os executivos de vários departamentos da organização, com conhecimento do mercado da empresa. Estes formam um comitê que tem a responsabilidade de desenvolver 
uma previsão de vendas. O comitê pode usar muitas informações (inputs) de todas as partes da organização e fazer com que os analistas do staff forneçam análises quando necessário. Essas previsões tendem a ser previsões de compromisso, não refletindo a tendência que poderia estar presente caso tivessem sido preparadas por um único indivíduo (Wanke e Julianelli, 2006). Outros métodos qualitativos e suas características podem ser obtidos em Heizer e Render, 2001.

Em relação aos métodos quantitativos, a Média Móvel, por necessitar de poucos dados históricos e ser de fácil implementação e manutenção, é um dos métodos mais difundidos. Todavia, este método apresenta algumas limitações no seu uso. Deve apenas ser empregado para previsões de curto prazo e para dados históricos irregulares, em que os componentes tendência e sazonalidade não estão presentes (Makridakis et al., 1998). Este método utiliza a média aritmética dos últimos $\mathrm{n}$ valores para prever o valor seguinte. Assim, a cada nova observação disponível, o valor mais antigo é descartado e o mais recente é inserido para o cálculo da nova média (Wanke e Julianelli, 2006). As desvantagens desse modelo estão relacionadas à falta de acurácia ao lidar com séries históricas que apresentam tendência ou sazonalidade já que, nesse método, a previsão para o próximo período envolve sempre a adição de novos dados e a desconsideração dos anteriores, além da média ser sensível a pequenas modificações de valores. Uma alternativa para amenizar esse erro é a utilização da média ponderada para tentar construir um padrão mais próximo à realidade. A desvantagem na utilização da Média Móvel Ponderada é a necessidade de conhecimento para determinar os pesos a serem utilizados (Davis et al., 2001).

O método Amortecimento Exponencial Simples (AES) pondera os valores utilizados na previsão de acordo com o tempo. Em outras palavras, o AES permite atribuir um maior peso em valores mais recentes, assumindo que estes são mais importantes na determinação do valor previsto (Wanke e Julianelli, 2006). Sua representação matemática pode ser dada por:

em que:

$$
z^{t+1}=\alpha z^{t}+(1-\alpha) \hat{z}^{t}
$$

- $z^{t+1}$ : previsão da demanda para o tempo $t+1$, feita no período atual t;

- $\alpha$ : coeficiente de amortecimento $(0 \leq \alpha \leq 1)$;

- $z^{t}$ : valor real observado no período $t$;

- $\hat{z}^{t}$ : previsão referente ao período $t$.

O coeficiente de amortecimento $\alpha$ pode ser interpretado como um fator de ponderação, determinando o quanto os valores mais recentes são mais importantes que os mais antigos para a previsão. Assim, quanto mais próximo de 1 for $\alpha$, a previsão será mais sensível ao último valor observado. Por outro lado, quanto mais próximo de 0 for $\alpha$, a previsão para cada período seguinte pouco será afetada pelo último valor observado, sendo cada vez mais próxima ao valor da última previsão (Wanke e Julianelli, 2006). Os modelos de AES também possuem sua precisão relacionada à estimativa inicial para $\hat{Z}^{t}$. Quando dados históricos estão disponíveis, pode-se usar uma média simples das $n$ observações mais recentes como $\hat{z}^{t}$, caso contrário, pode-se utilizar a observação mais recente, ou fazer uma estimativa subjetiva. O AES também não deve ser aplicado a séries temporais que apresentem tendência, uma vez que os valores das previsões apresentam um viés, de forma que ficam sistematicamente abaixo dos reais.

Para realizar previsão de demanda considerando tendência e sazonalidade pode-se citar, dentre diversos métodos baseados em estudos de séries temporais, os modelos de Amortecimento Exponencial de Holt-Winters. Estes modelos descrevem apropriadamente os dados em que se verifica a ocorrência de tendência linear, além de componente de sazonalidade (Pelegrini e Flogiatto, 2000).

Em Morettin e Toloi (2004), os autores destacam que as vantagens desse modelo são: fácil entendimento, aplicação não dispendiosa, adequada para série com padrão de comportamento mais geral. E que as desvantagens são: dificuldades de determinar os valores mais apropriados das constantes de suavização e/ou impossibilidade de estudar as propriedades estatísticas, tais como média e variância da previsão e, consequentemente, a construção de um intervalo de confiança. 
Existem dois modelos de Amortecimento Exponencial de Holt-Winters, o Aditivo e o Multiplicativo. O modelo de Amortecimento Exponencial de Holt-Winters Aditivo é utilizado quando a amplitude da variação sazonal se mantém constante, ou seja, a diferença entre o maior e o menor ponto de demanda nos ciclos permanece constante com o passar do tempo. $\mathrm{O}$ Amortecimento Exponencial Holt-Winters Multiplicativo é utilizado quando a amplitude da variação sazonal aumenta com o tempo, ou seja, a diferença entre o maior e o menor ponto de demanda nos ciclos cresce com o passar do tempo (Pelegrini e Flogiatto, 2000).

No Quadro 1, são apresentadas as equações básicas para os dois modelos.

Quadro 1: Parâmetros dos modelos de Amortecimento Exponencial Holt-Winters.

\begin{tabular}{|c|c|c|}
\hline Nível & Aditivo & Multiplicativo \\
\hline Tendência & $L_{t}=\alpha\left(Y_{t}-S_{t-s}\right)+(1-\alpha)\left(L_{t-1}+b_{t-1}\right)$ & $L_{t}=\alpha \frac{Y_{t}}{S_{t-s}}+(1-\alpha)\left(L_{t-1}+b_{t-1}\right)$ \\
\hline Sazonalidade & $b_{t}=\beta\left(L_{t}-L_{t-1}\right)+(1-\beta) b_{t-1}$ & $b_{t}=\beta\left(L_{t}-L_{t-1}\right)+(1-\beta) b_{t-1}$ \\
\hline Previsão & $S_{t}=\gamma\left(Y_{t}-L_{t}\right)+(1-\gamma) S_{t-s}$ & $S_{t}=\gamma \frac{Y_{t}}{L_{t}}+(1-\gamma) S_{t-s}$ \\
\hline
\end{tabular}

Em que:

Fonte: Baseado em Caiado, 2016.

$L_{t}-$ Nível da Série.

$b_{t}-$ Tendência.

$S_{t}-$ Componente Sazonal.

$F_{t+m}$ - Previsão para o período $\mathrm{m}$.

$Y_{t}-$ Valor Observado.

Observe que a escolha entre o método Aditivo ou Multiplicativo de Holt-Winters ocorre de acordo com a análise prévia dos dados, verificando se os ciclos de sazonalidade estão aumentando (quando se compara os picos de demanda) ao longo do tempo.

Segundo Heizer e Render (2001), as empresas aplicam métodos híbridos de previsão de demanda, em geral, fazendo iterações e/ou interações entre métodos qualitativos e quantitativos. Cabe mencionar ainda que a escolha do método de previsão utilizado, como mencionado anteriormente, depende de uma análise prévia dos dados históricos existentes.

Em Werner e Ribeiro (2006) a estrutura básica do modelo composto de previsão contempla a interação entre as formas de integração, conforme proposto por Webby e O'Connor (1996). Contudo, esses autores sugerem apenas a reunião destas duas formas de integração de previsões, a combinação de previsões e o ajuste baseado na opinião, sugerindo o uso de uma estrutura muito simples para lidar com as complexidades observadas em casos reais.

Tal fato gerou a necessidade de detalhar esta sugestão através de um modelo mais completo, que permita incorporar mais informações ao processo de previsão, bem como às tomadas de decisões inerentes a este processo. Sendo assim, o modelo é formado pela combinação de três previsões individuais. Essas previsões individuais, baseadas em informações de dados históricos, de dados econômicos e na opinião de especialistas, são reunidas de maneira a permitir a obtenção de uma previsão intermediária. A previsão intermediária, por sua vez, é ajustada para formar a previsão final.

O modelo composto, citado acima, está estruturado em seis etapas: (i) verificação da existência de dados e de especialistas; (ii) obtenção das previsões individuais; (iii) cálculo dos pesos das previsões individuais; (iv) obtenção da previsão combinada; (v) verificação da necessidade de fazer ajuste; e (vi) obtenção da previsão final. Este estudo tomou por base as ideias estruturais que foram apresentadas por (Werner e Ribeiro, 2006). 
Quando uma empresa decide utilizar técnicas quantitativas de previsão de demanda, o conhecimento e julgamento dos analistas, que são considerados nos modelos, representam um importante papel no processo de decisão. Até mesmo durante a utilização de técnicas quantitativas, o julgamento do gestor está presente, seja quando decide entre quais métodos utilizar, seja quando seleciona os dados que serão utilizados e realiza os tratamentos que julgam necessários (por exemplo, expurgo de outliers) (Wanke e Julianelli, 2006). Detalhes sobre previsões podem ser encontrados também Makridakis et al. (1998).

Os autores, pela característica do trabalho desenvolvido (pesquisa-ação), junto a empresa optaram por seguir o modelo de previsão descrito em Wanke e Julianelli (2006). Os métodos qualitativos e quantitativos usados serão detalhados junto a análise de dados.

\subsection{Cálculo de Necessidades de Materiais}

Segundo Heizer e Render (2001) o programa mestre da produção (MPS - master production scheduling) especifica quais itens devem ser feitos e em que ordem, em outras palavras, o MPS, ainda segundo os autores, fornece o que é necessário para satisfazer a demanda e cumprir o plano de produção. Em geral, o programa mestre de produção considera um ciclo de produção e fornece a informação do que deve ser produzido, em que quantidade e em que momento. Para fazer essa programação é necessário que cada produto tenha sua lista de materiais. A lista de materiais declara toda a composição do produto final, detalhando os itens necessários e sua necessidade bruta.

Para exemplificar, no caso estudado nesse trabalho, pode-se ter como exemplo os componentes para uma barra de corte, que será denotada por Produto 1 (A). Para a produção do Produto 1 são necessários: 1 barra chata $(B)$ de 13 pés, 52 lâminas de corte $(C), 1$ meia lâmina de corte direita (D), 3 grampos de fixação maior (E), 98 rebites (F), 0,1330 litros de tinta esmalte nitro sintético preto $(\mathrm{G})$ e 0,0057 litros de thinner $(\mathrm{H})$. Alguns itens descritos para o Produto 1 necessitam de outros itens para serem produzidos, como detalhamos a seguir. Cada barra chata de 13 pés origina-se do aço chato ABNT1045 (I) trefilado (denominado pela empresa por $\mathrm{H} 2$ ), cada lâmina possui um blank de lâmina (J), cada meia lâmina origina-se com $0,085 \mathrm{KG}$ da bobina chapa $1070 \mathrm{ABNT}(\mathrm{K})$ e cada grampo de fixação (L) possui como material $0,0028 \mathrm{~kg}$ de arame recozido. Por fim, cada blank de lâmina possui $0,114 \mathrm{~kg}$ de bobina chapa 1070 ABNT (M).

Pode-se separar a necessidade dos itens por níveis, sendo o produto final alocado ao nível 0 . No nível seguinte são descritos os itens necessários de forma imediata para a produção de um produto do nível anterior e esse raciocínio se segue até descrever todos os itens necessários para a produção. Toda a lista de materiais pode ser representada por uma Árvore do Produto. Na árvore é colocado o nível de cada item produzido, segundo sua dependência. Na Figura 1, a lista de materiais foi representada em uma Árvore do Produto. Como pode-se perceber na Figura 1, a demanda para alguns itens do nível 2 e 3, é completamente dependente da barra de corte.

Desse modo, essa estrutura tem 4 níveis: 0, 1, 2, e 3. Existem seis pais: A, B, C, D, E e J. Cada item pai tem pelo menos um nível abaixo de si. Os itens B, C, D, E, F, G, H, I e J são componentes porque cada item tem pelo menos um nível acima de si. Nessa estrutura, B, C, D, $\mathrm{E}$ e $\mathrm{J}$, são ao mesmo tempo pais e componentes. O número localizado no canto superior direito indica quantas unidades do item são necessárias para fazer o item imediatamente acima dele.

Uma vez desenvolvida a estrutura do produto, pode-se determinar o número de unidades de cada item necessário para satisfazer a demanda de um pedido da barra. Considerando a necessidade de 36 barras, para um determinado período, tem-se o exemplo de necessidades nesse período. Para obter o valor total da necessidade bruta de cada componente basta multiplicar a demanda do pai pela necessidade unitária para a produção do item pai. Os cálculos do exemplo estão feitos na Tabela 1 . Na primeira coluna estão identificados os itens que serão calculadas as necessidades. Na segunda coluna tem-se a regra para determinar a quantidade necessária, por exemplo, a demanda do item B é dada por uma vez a demanda do item A, uma vez que, para produzir uma unidade do item A é necessário apenas uma unidade do item B. De modo semelhante, temos na segunda linha que para a produção de uma unidade do item A são 
necessárias 52 unidades do item $\mathrm{C}$, desse modo 52 vezes a demanda de A fornece o total necessário do item C. A terceira coluna representa o cálculo da coluna Necessidade com os valores substituídos e na última coluna foi atribuído o valor final da demanda.

Figura 1. Árvore do Produto 1.



Fonte: Elaborada pelos autores.

Tabela 1: Necessidade de matéria-prima do produto A.

\begin{tabular}{|r|r|r|r|}
\hline Item & \multicolumn{1}{|c|}{ Necessidade } & \multicolumn{1}{|c|}{ Cálculos } & \multicolumn{1}{|c|}{ Resultado } \\
\hline B & $1 \times \mathrm{A}$ & $1 \times 36$ & 36 unidades \\
\hline C & $52 \times \mathrm{A}$ & $52 \times 36$ & 1872 unidades \\
\hline D & $1 \times \mathrm{A}$ & $1 \times 36$ & 36 unidades \\
\hline E & $3 \times \mathrm{A}$ & $3 \times 36$ & 108 unidades \\
\hline F & $58 \times \mathrm{A}$ & $58 \times 36$ & 2088 unidades \\
\hline G & $0,1330 \times \mathrm{A}$ & $0,1330 \times 36$ & 4,788 litros \\
\hline H & $0,0057 \times \mathrm{A}$ & $0,0057 \times 36$ & 0,2052 litros \\
\hline I & $1 \times \mathrm{B}$ & $1 \times 12$ & 12 barras \\
\hline J & $1 \times \mathrm{C}$ & $1 \times 1872$ & 1872 unidades \\
\hline K & $0,085 \times \mathrm{D}$ & $0,085 \times 36$ & 3,06 quilos \\
\hline L & $0,0028 \times \mathrm{E}$ & $0,0028 \times 108$ & 0,3024 quilos \\
\hline M & $0,1140 \times \mathrm{J}$ & $0,1140 \times 1872$ & 213,408 quilos \\
\hline
\end{tabular}

Fonte: Elaborada pelos autores.

Os cálculos apresentados na Tabela 1 considera apenas o Produto 1 estudado neste artigo. Em uma empresa é possível que produtos distintos tenham itens em comum. Desse modo, para saber a necessidade de cada item em um período é necessário repetir o cálculo da Tabela 1 para todos os produtos da empresa e depois agregar as demandas dos itens.

Uma das atividades do MRP é obter a demanda bruta de cada item, ou seja, considerando que o MPS e a lista de materiais foi calculada para cada produto da empresa, há a necessidade de agregar as demandas de cada item, considerando a necessidade de produção de todos os produtos. Para mais detalhes sobre as demais atividades do MRP pode-se consultar, por exemplo, Heizer e Render (2001).

Observe que a simples soma das demandas fornece uma quantidade em comprimento de barras de aço chato, incluindo no exemplo, inferior à que realmente é necessária, pois pode não 
ser possível cortar a quantidade exata de itens das barras de aço chato de tal modo que não tenha desperdício, causando pelo arranjo das peças na hora do corte.

\subsection{Problema de Corte Unidimensional}

Segundo Arenales et al. (2007), problemas de corte de estoque consistem na otimização do processo de corte de peças maiores, disponíveis em estoque, para a produção de peças menores, os quais podem ser modelados por um problema de otimização linear inteira de grande porte. Este processo consiste em definir os possíveis padrões de corte, isto é, como as peças maiores devem ser cortadas para a produção de peças menores, e as variáveis de decisão representam o número de vezes que as peças maiores são cortadas, segundo um padrão.

O problema de corte de estoque unidimensional consiste em obter um conjunto de pedidos de peças menores, com demanda conhecida $d_{i}, i=1, \ldots, m$, que chamamos de itens, de comprimentos $l_{i}, i=1, \ldots, m$, a partir de um estoque de objetos (barras, bobinas, etc.) de comprimento $L$. Em outras palavras, o problema consiste em produzir os itens demandados a partir do corte dos objetos em estoque, atendendo a demanda e de modo que o número de objetos em estoque necessários para satisfazer a demanda seja minimizado. Não é permitido o excesso de produção e os objetos em estoque devem ser cortados completamente, ou seja, não é permitido cortar uma parte de um objeto e devolver o restante para o estoque. Pedaços do corte que não sejam os itens demandados são considerados perda.

Para descrever o modelo, apresentado em Arenales et al. (2007), são definidas algumas variáveis e parâmetros. O primeiro parâmetro considerado é o padrão de corte, que nada mais é do que a maneira como um objeto em estoque é cortado para a produção dos itens demandados. Para cada padrão de corte é associado um vetor m-dimensional que contabiliza os itens produzidos:

$$
a=\left(\alpha_{1}, \alpha_{2}, \ldots, \alpha_{m}\right)
$$

em que $\alpha_{i}$ é a quantidade de itens do tipo $i$ no padrão de corte a.

Observe que um vetor $\mathrm{a}=\left(\alpha_{1}, \alpha_{2}, \ldots, \alpha_{\mathrm{m}}\right)$ corresponde a um padrão de corte se $\mathrm{e}$ somente se satisfizer:

$$
\begin{aligned}
& \ell_{1} \alpha_{1}+\ell_{2} \alpha_{2}+\cdots+\ell_{m} \alpha_{m} \leq L \\
& 0 \leq \alpha_{1} \leq d_{i}, i=1, \ldots, m \text { e inteiros, }
\end{aligned}
$$

em que $d_{i}$ é a demanda do item $i$, que não deve ser excedida.

Após a definição dos padrões de corte de cada matéria-prima, o próximo passo será determinar o número de vezes que cada padrão de corte que é obtido na resolução do modelo matemático. Considerando $x_{j}$ como o número de vezes que o objeto é cortado no padrão $j$ e $n$ a quantidade de padrões de corte. O modelo matemático para o problema de corte de estoque proposto em Gilmore e Gomory (1961) pode ser escrito do seguinte modo:

$$
\begin{array}{ll}
\text { Minimizar } & f(x)=\sum_{j=1}^{n} x_{i} \\
\text { Sujeito a: } & \sum_{j=1}^{n} a_{i j} x_{i}=d_{i}, \forall i \in\{1, \ldots, m\} \\
& x_{1}, \ldots, x_{n} \geq 0 \text { e inteiros. }
\end{array}
$$

O problema de corte de estoque unidimensional pode ser modelado de diferentes formas. Outras maneiras de modelagem desse problema podem ser encontrados em Arenales et al. (2007). A escolha do modelo (4)-(6) para resolver o problema de corte de estoque unidimensional, nesse trabalho, foi feita pela facilidade na consideração dos padrões de corte usados na empresa e sugestões de novos padrões.

Cabe mencionar ainda que, nesse trabalho, o modelo de corte de estoque unidimensional é aplicado em cada período do horizonte de planejamento para obter uma quantidade mínima de placas que precisam ser compradas pela empresa. Em Arenales et al. (2007), apenas para os casos em que a restrição (5) considera o atendimento exatamente igual a demanda, tem-se a 
demonstração que minimizar o número de objetos utilizados é equivalente a minimizar a perda total gerada pelos cortes dos padrões. Além disso, não há a preocupação com o balanço de estoque entre os períodos, uma vez que, nesse momento a empresa está em uma decisão estratégica. Para decisões táticas ou operacionais o controle do estoque e dos cortes das placas podem ser realizados com modelos mais específicos, como o apresentado em Poldi e Arenales (2010). No trabalho de Poldi e Arenales (2010) os autores apresentam um modelo de programação linear, com uso de padrões de corte, para um problema de corte de estoque unidimensional multi-período.

Ainda em relação ao operacional, durante o planejamento operacional existe o problema de reaproveitamento de sobras das barras utilizadas na produção dos itens. Embora seja um problema importante para diminuir as perdas e auxiliar na gestão do estoque, o problema de perdas e reutilização de sobras da barra de aço não serão tratados nesse trabalho. Problemas relacionadas a perdas ou sobras em corte de estoque unidimensional podem ser encontrados em Cherri (2006), Loeblein et al. (2012) e Salles-Neto et al. (2014).

\section{Materiais e Métodos}

Como mencionado na Introdução desse trabalho, o objetivo do trabalho é identificar os problemas relacionados ao dimensionamento do lote de compras, de um produto específico, da empresa e fornecer um procedimento para tomar a decisão do tamanho do lote. Embora a empresa faça uma previsão de vendas, descrita com mais detalhes na Seção 4.2, e um dimensionamento do lote de compra a partir da previsão de vendas, existe uma subjetividade na decisão. Tal subjetividade ocorre na conexão da previsão da demanda dos itens produzidos com as perdas no corte das barras de aço. Desse modo, segundo Thiollent (2007), o presente trabalho é caracterizado como uma pesquisa-ação.

Ainda segundo Thiollent (2007) na pesquisa-ação há dois objetivos, sendo o primeiro o Objetivo Técnico, que está na contribuição com as soluções propostas e ações decorrentes da pesquisa que irão transformar a ação. O segundo é o Objetivo Científico que está relacionado ao aumento da base de conhecimento de determinadas situações. Nesse contexto, pode-se dizer que o Objetivo Técnico desse trabalho está na sistematização do processo do dimensionamento do lote de compras da empresa. Esse objetivo é realizado junto a gestores da empresa, que a cada sugestão de ferramentas de apoio a decisão existente na literatura, decidem a melhor opção para a empresa. O Objetivo Científico ocorre com a identificação de um problema prático em que modelos clássicos existentes são aplicados para auxiliar a tomada de decisão.

Resumidamente, o processo desenvolvido para o dimensionamento do lote de compras pode ser descrito nas seguintes etapas. Primeiro é feita a previsão mensal dos produtos da empresa para o período de um ano, ou seja, a previsão contém o período de doze meses. Determinada a previsão da demanda definida é feito o cálculo da necessidade de materiais. Esse cálculo é, aplicando o mesmo procedimento realizado pelo MRP porém, no lugar do plano de produção, os cálculos são feitos utilizando como dado de entrada a previsão de vendas realizada na primeira etapa. Após o cálculo da demanda bruta da barra de aço, aplica-se mês a mês o modelo de corte de estoque para determinar a quantidade mínima de barras de aço que devem ser compradas.

Para a previsão da demanda é necessário verificar qual o melhor método (ou misturas de métodos) será utilizado na previsão. Para isso tem que ser feita uma análise da existência e facilidade de acesso a dados históricos de vendas dos produtos além de verificar as propriedades dos dados (sazonalidade, tendência, entre outros).

Após a previsão, para o cálculo da necessidade de materiais, a empresa precisa a árvore do produto para todos os produtos analisados. Com isso, pode-se usar a previsão da demanda para calcular a necessidade futura dos materiais, usando o raciocínio aplicado no MRP. Lembrando que os cálculos relacionados o controle de estoque e tempo de pedido não serão considerados nessa previsão.

Com a necessidade bruta dos materiais, um modelo de otimização linear inteira é selecionado para obter uma previsão mais próxima do lote de compra da matéria-prima. $\mathrm{O}$ 
modelo escolhido tem que levar em consideração o tipo de decisão a ser tomada (estratégica, tática ou operacional). Na Seção 4, a seguir, é descrita cada uma das etapas da ferramenta (processo descrito) para obter o tamanho do lote de compra em cada período do horizonte de planejamento.

\section{Pesquisa-Ação e Resultados}

Nessa seção são fornecidos detalhes sobre a empresa e o problema estudado, bem como as justificativas e os resultados obtidos com a aplicação do método. Em cada subseção serão dados os detalhes das ações realizadas pela empresa e do processo utilizado.

\subsection{Apresentação do Problema}

A empresa, objeto de estudo desse trabalho, está há 50 anos no mercado e está situada a aproximadamente $70 \mathrm{~km}$ de Ribeirão Preto e possui um território de aproximadamente 23,5 mil metros quadrados e empresa cerca de 200 funcionários. A empresa é líder na produção de peças para colheitadeiras e tratores. Faz produtos agrícolas e de fundição para o mercado, além de desenvolver produtos para máquinas agrícolas.

Os gestores da empresa fazem um planejamento estratégico dos pedidos de compra de barras de aço que serão realizadas ao longo do próximo ano. O dimensionamento do lote em cada pedido é feito de modo subjetivo e baseado na experiência do gestor responsável pela produção. Para tomar a decisão, o gestor tem como base a previsão de venda do próximo ano, fornecida pelo setor responsável, e partir da previsão de venda obtêm uma previsão dos tamanhos dos lotes que serão solicitados no próximo ano. Cabe mencionar que o fornecedor das barras de aço permite que a empresa modifique o tamanho das barras de aço que serão compradas, porém essa variação é limitada e por motivos operacionais não pode ser modificada a cada período. Porém, como não há outras ferramentas quantitativas para auxiliar a tomada de decisão do tamanho da barra e a quantidade, o gestor não consegue sugerir modificações no tamanho das barras que serão solicitadas.

Desse modo, pode-se dizer que não uma padronização na relação entre o cálculo da quantidade de produtos vendidos e a necessidade real de barras de aço que serão compradas. Assim, criar uma padronização no cálculo dessa necessidade e ter uma ferramenta de apoio para estimar o tamanho do lote irá auxiliar o gestor a planejar os pedidos de compra do ano seguinte.

\subsection{Previsão Agregada da Demanda}

Como mencionado, será utilizado o modelo de previsão dado por Werner e Ribeiro (2006). No modelo proposto pelos autores, a previsão consiste em seis etapas: (i) verificação da existência de dados e de especialistas; (ii) obtenção das previsões individuais; (iii) cálculo dos pesos das previsões individuais; (iv) obtenção da previsão combinada; (v) verificação da necessidade de fazer ajuste; e (vi) obtenção da previsão final. Foi decidido esse modelo, pois ele se adequa melhor ao método de Pesquisa-ação, uma vez que o modelo propõe iterações e interações entre os métodos de previsão e os especialistas da empresa. A seguir é descrito cada uma das etapas desenvolvidas.

$\mathrm{Na}$ Etapa (i), sobre verificação da existência de dados e de especialistas. A empresa possui um bom histórico de venda de seus produtos e uma flexibilidade no envolvimento dos especialistas junto à previsão de vendas de seus produtos. Foi estipulado um levantamento das vendas realizadas nos últimos três anos dos produtos da empresa, para que se pudesse fazer uma boa previsão de vendas, sem desconsiderar os métodos propostos incialmente, citados na Seção 2. Dado o histórico de vendas de produtos da empresa, foram desconsiderados do estudo os produtos que não são mais vendidos pela empresa ou não utilizam o $\mathrm{H} 2$ como matéria-prima, restando no final um total de 111 produtos finais.

Ainda na primeira fase do modelo de previsão, foram selecionados três funcionários da empresa, que são de fundamental importância no método de previsão utilizado pela empresa no 
início do estudo. O primeiro funcionário é o gerente da área de estamparia e, também, um dos diretores da empresa. O segundo funcionário da empresa possui 23 anos de casa, tendo assim experiência na produção da empresa. O terceiro é um engenheiro de produção que conhece os procedimentos de previsão e é da área de negócios agrícolas.

Em relação aos dados históricos da empresa, os valores de venda dos últimos três anos foram organizados em tabelas, como, por exemplo, os dados apresentados de um dos produtos estudado, vide Tabela 2 .

Tabela 2: Dados de vendas do Produto 1.

\begin{tabular}{|l|c|c|c|c|c|c|c|c|c|c|c|c|}
\cline { 2 - 14 } \multicolumn{1}{c|}{} & Jan. & Fev. & Mar. & Abril & Maio & Junho & Julho & Agosto & Set. & Out. & Nov. & Dez. \\
\hline 2014 & 93 & 4 & 63 & 24 & 9 & 0 & 20 & 24 & 19 & 49 & 53 & 5 \\
\hline 2015 & 43 & 30 & 34 & 8 & 0 & 4 & 2 & 1 & 9 & 17 & 4 & 46 \\
\hline 2016 & 10 & 37 & 5 & 16 & 2 & 20 & 5 & 4 & 6 & 17 & 20 & 19 \\
\hline
\end{tabular}

Fonte: Elaborada pelos autores.

A Tabela 2 é um exemplo de como os dados foram organizados para o estudo. Os anos foram alocados nas linhas e em cada coluna foram atribuídos os meses. Desse modo, em cada célula é fornecida a quantidade vendida do Produto 1. Assim, foram construídas 111 tabelas (uma para cada produto estudado) semelhantes a Tabela 2.

A Etapa (ii) "obtenção das previsões individuais" e a Etapa (iii) "cálculo dos pesos das previsões individuais" foram feitas pelo método de previsão de vendas de Amortecimento Exponencial Aditivo de Holt-Winter. O método escolhido se justifica pois, após análise dos dados com auxílio de planilha eletrônica, neste caso o software Microsoft Excel, e a ferramenta de trabalho Solver, foi verificada a existência de tendências e sazonalidades nos dados históricos. O fato de ter sazonalidade e tendência inviabiliza, nesse estudo, as previsões com uso de médias ou suavizações exponenciais.

Ainda com o auxílio do software foi analisada a sazonalidade de alguns produtos e verificou-se que não há aumento da amplitude da variação da sazonalidade, escolhendo assim o método aditivo para a aplicação da previsão de demanda (equações da coluna "aditivo" do Quadro 1). Para exemplificar o estudo feito, apresentamos a Figura 1 a) em que apresenta a série temporal de um produto estudado, ou seja, a demanda dos últimos três anos e em b) o gráfico para verificação da sazonalidade. Na Figura 1 a) é possível notar que ao longo do tempo a amplitude de variação oscila, por exemplo, o pico em 2014 é maior do que os picos em 2016. Tal variação da amplitude fica mais evidente na Figura 1 b) em que cada linha representa a demanda de cada ano ao longo dos meses.

Após a decisão do método utilizado para a previsão da demanda, foram obtidos os parâmetros do modelo: $\alpha, \beta$ e $\gamma$. Esses parâmetros são calculados com o auxílio do software Microsoft Excel 2010 que determina os valores que melhor se encaixam para a diminuição do erro de previsão. O primeiro parâmetro alpha, significa o nível, beta trata-se da tendência e por fim gama especifica a sazonalidade. Para obter os parâmetros, utilizados na previsão, foram usados os dados de venda de 2013 a 2015. Após o cálculo dos parâmetros, foi feita a verificação da qualidade da previsão junto ao modelo para o ano de 2016. Em outras palavras, para determinar os parâmetros e qualidade dos valores, foram usados quatro anos de histórico de venda.

Os três primeiros anos $(2013,2014$ e 2015) foram utilizados para obter os parâmetros e o ano de 2016 foi usado para comparar a previsão realizada. A Tabela 3 apresenta os valores dos parâmetros obtidos para cada um dos produtos estudados e o erro quadrado da previsão, quando obtidos com os dados de 2013, 2014 e 205 e aplicados nos anos de 2014-2015-2016.

Cabe mencionar que, antes de apresentar as tabelas com os valores das previsões, os dados reais e os erros das previsões pelo método proposto, os autores desse trabalho, fizeram as previsões com a média móvel e suavização exponencial, obtendo previsões muito piores do que as obtidas pelo método aditivo de Holt-Winter. Os resultados foram apresentados para os três especialistas que concordaram em eliminar as previsões pela média e suavização exponencial. 
Figura 1. Gráfico de vendas dos últimos três anos.

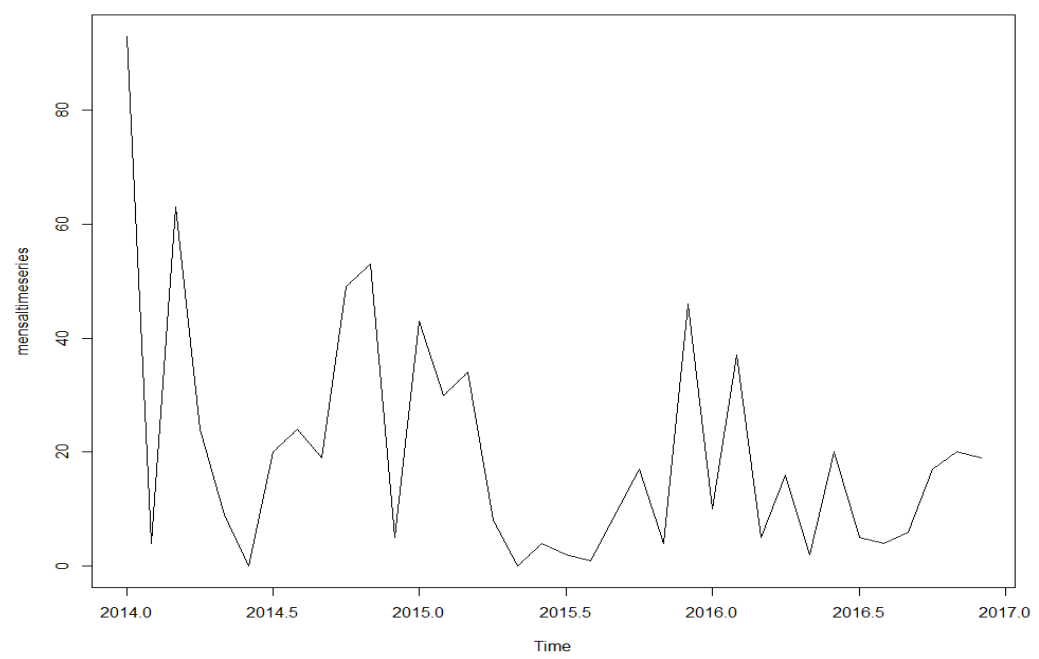

a) Série Temporal da demanda



b) Variação mensal das demandas

Fonte: Elaborada pelos autores com auxílio do software R.

A Etapa (iv) "Obtenção da previsão combinada", a Etapa (v) "Verificação da necessidade de fazer ajuste" e a Etapa (vi) "Obtenção da previsão final" foram feitas em conjunto com os especialistas até que todos concordassem com a previsão final. A Etapa (iv) foi estipulada pelos especialistas que a previsão combinada tem como referência os meses do ano, isso também justifica a organização das tabelas de cada produto. Em outras palavras, foi decidido um horizonte de planejamento de um ano, dividido mês a mês, para decidir a necessidade de compra da matéria-prima.

Para explicar a Etapa (v) é necessário entender o processo de previsão que a empresa realizava até o momento. Para a previsão da demanda, o especialista responsável aplicava inicialmente o método ingénuo de previsão, ou seja, considerava que o que foi vendido no mesmo mês no ano anterior. Após essa previsão o especialista verificava se existia alguma informação relevante sobre a economia do país para verificar alguma influência externa que poderia impactar na demanda e por último fazia entrevistas junto a alguns representantes da empresa. 
Tabela 3: Parâmetros e Erro de Previsão.

\begin{tabular}{|c|c|c|c|c|c|c|c|c|c|}
\hline Produto & $\alpha$ & $\beta$ & $\gamma$ & Erro & Produto & $\alpha$ & $\beta$ & $\gamma$ & Erro \\
\hline 1 & 0,02 & 1,00 & 0,00 & 6809,85 & 57 & 0,92 & 0,00 & 0,00 & 276,27 \\
\hline 2 & 0,01 & 0,58 & 0,00 & 980,28 & 58 & 0,01 & 1,00 & 0,00 & 3649,68 \\
\hline 3 & 0,00 & 0,03 & 0,00 & 3444,73 & 59 & 0,02 & 0,60 & 0,00 & 358,23 \\
\hline 4 & 0,01 & 1,00 & 0,00 & 35653,18 & 60 & 0,15 & 0,05 & 0,00 & 406,19 \\
\hline 5 & 0,00 & 1,00 & 0,00 & 59276,18 & 61 & 1,00 & 0,00 & 0,09 & 125609,57 \\
\hline 6 & 0,20 & 0,00 & 0,00 & 55846,94 & 62 & 0,83 & 0,00 & 0,02 & 866,63 \\
\hline 7 & 0,02 & 1,00 & 0,00 & 60978,52 & 63 & 0,52 & 0,01 & 0,00 & 46104,89 \\
\hline 8 & 0,31 & 0,01 & 0,00 & 23784,47 & 64 & 0,13 & 0,00 & 0,00 & 5822,67 \\
\hline 9 & 0,39 & 0,00 & 0,00 & 111601,45 & 65 & 0,02 & 0,56 & 0,00 & 733,70 \\
\hline 10 & 0,03 & 1,00 & 0,00 & 2296,51 & 66 & 0,01 & 1,00 & 0,00 & 581,26 \\
\hline 11 & 0,02 & 1,00 & 0,00 & 2420,31 & 67 & 0,00 & 0,04 & 0,00 & 3694,53 \\
\hline 12 & 0,66 & 1,00 & 0,16 & 4572,83 & 68 & 0,10 & 1,00 & 0,00 & 5542,95 \\
\hline 13 & 0,38 & 0,00 & 0,00 & 29,21 & 69 & 0,05 & 1,00 & 0,00 & 22353,00 \\
\hline 14 & 0,07 & 0,21 & 0,00 & 298,37 & 70 & 0,00 & 0,02 & 0,00 & 564,13 \\
\hline 15 & 0,37 & 1,00 & 0,00 & 171,39 & 71 & 0,20 & 0,13 & 0,01 & 41,36 \\
\hline 16 & 0,55 & 0,97 & 0,09 & 5,74 & 72 & 0,49 & 0,00 & 0,00 & 2441,64 \\
\hline 17 & 0,01 & 1,00 & 0,00 & 136,20 & 73 & 0,30 & 0,00 & 0,00 & 929,52 \\
\hline 18 & 0,02 & 1,00 & 0,00 & 39,13 & 74 & 0,00 & 0,05 & 0,00 & 14958,28 \\
\hline 19 & 0,23 & 0,00 & 0,00 & 35589,51 & 75 & 0,52 & 0,00 & 0,00 & 513,60 \\
\hline 20 & 0,18 & 1,00 & 0,00 & 277,69 & 76 & 0,00 & 1,00 & 0,00 & 32680,22 \\
\hline 21 & 0,00 & 0,00 & 0,00 & 129367,86 & 77 & 0,43 & 0,00 & 0,00 & 2237,81 \\
\hline 22 & 0,05 & 0,21 & 0,00 & 2925,42 & 78 & 0,01 & 1,00 & 0,00 & 13441,91 \\
\hline 23 & 0,00 & 0,23 & 0,00 & 20623,56 & 79 & 0,01 & 0,88 & 0,00 & 724,14 \\
\hline 24 & 0,04 & 1,00 & 0,00 & 4093,87 & 80 & 0,07 & 0,17 & 0,15 & 58,88 \\
\hline 25 & 0,05 & 0,28 & 0,00 & 656,28 & 81 & 0,01 & 1,00 & 0,00 & 3472,50 \\
\hline 26 & 0,22 & 0,30 & 0,00 & 218,60 & 82 & 0,12 & 0,49 & 0,00 & 198,34 \\
\hline 27 & 0,01 & 1,00 & 0,00 & 49174,98 & 83 & 0,21 & 0,00 & 0,00 & 1300,45 \\
\hline 28 & 0,23 & 1,00 & 0,00 & 31,80 & 84 & 0,43 & 0,00 & 0,00 & 2237,97 \\
\hline 29 & 0,01 & 1,00 & 0,00 & 73866,98 & 85 & 0,06 & 0,88 & 0,00 & 4109,56 \\
\hline 30 & 0,02 & 0,00 & 0,00 & 72,87 & 86 & 0,04 & 1,00 & 0,00 & 831,80 \\
\hline 31 & 0,00 & 0,16 & 0,00 & 1072,68 & 87 & 0,04 & 1,00 & 0,00 & 972,69 \\
\hline 32 & 0,00 & 0,05 & 0,00 & 7,10 & 88 & 0,02 & 0,60 & 0,00 & 355824,35 \\
\hline 33 & 0,01 & 1,00 & 0,00 & 44941,36 & 89 & 0,00 & 0,03 & 0,00 & 52081,57 \\
\hline 34 & 0,01 & 1,00 & 0,00 & 1219,72 & 90 & 0,46 & 0,67 & 0,00 & 799,24 \\
\hline 35 & 0,01 & 1,00 & 0,00 & 1589,57 & 91 & 0,20 & 1,00 & 0,00 & 720,36 \\
\hline 36 & 0,21 & 0,84 & 0,16 & 1,50 & 92 & 0,07 & 1,00 & 0,00 & 201926,75 \\
\hline 37 & 0,01 & 1,00 & 0,00 & 440,75 & 93 & 0,02 & 1,00 & 0,00 & 23638,64 \\
\hline 38 & 0,01 & 1,00 & 0,00 & 340,03 & 94 & 0,03 & 1,00 & 0,00 & 4307,96 \\
\hline 39 & 0,01 & 1,00 & 0,00 & 2261,49 & 95 & 0,00 & 0,25 & 0,00 & 215,17 \\
\hline 40 & 0,01 & 1,00 & 0,00 & 422,38 & 96 & 0,05 & 0,43 & 0,00 & 336,96 \\
\hline 41 & 0,03 & 0,30 & 0,00 & 221,74 & 97 & 0,02 & 0,38 & 0,00 & 777,16 \\
\hline 42 & 0,01 & 1,00 & 0,00 & 669,79 & 98 & 0,13 & 0,75 & 0,01 & 831,68 \\
\hline 43 & 0,08 & 0,14 & 0,07 & 105,45 & 99 & 0,01 & 1,00 & 0,00 & 2944,15 \\
\hline 44 & 0,50 & 0,03 & 0,38 & 12,86 & 100 & 0,00 & 0,32 & 0,00 & 11000,05 \\
\hline 45 & 0,00 & 0,00 & 0,00 & 751,20 & 101 & 0,42 & 0,49 & 0,02 & 2277,53 \\
\hline 46 & 0,15 & 0,03 & 0,00 & 718,20 & 102 & 0,07 & 1,00 & 0,00 & 164,91 \\
\hline 47 & 0,08 & 0,03 & 0,00 & 358,32 & 103 & 1,00 & 0,65 & 0,00 & 3256,25 \\
\hline 48 & 0,16 & 0,02 & 0,00 & 8534,53 & 104 & 0,04 & 0,72 & 0,00 & 331,69 \\
\hline 49 & 0,01 & 1,00 & 0,00 & 1335,69 & 105 & 0,01 & 0,13 & 0,02 & 6398,49 \\
\hline 50 & 0,41 & 0,06 & 0,03 & 48,80 & 106 & 0,00 & 0,17 & 0,00 & 9472,45 \\
\hline 51 & 0,02 & 0,22 & 0,00 & 3308,28 & 107 & 0,05 & 1,00 & 0,00 & 785,89 \\
\hline 52 & 0,0 & 1,00 & 0,00 & 2396,88 & 108 & 0,01 & 1,00 & 0,00 & 723,42 \\
\hline 53 & 0,00 & 0,32 & 0,00 & 12,19 & 109 & 0,01 & 1,00 & 0,00 & 581,26 \\
\hline 54 & 0,07 & 0,01 & 0,00 & 88,44 & 110 & 0,10 & 1,00 & 0,00 & 8236,60 \\
\hline 55 & 0,01 & 1,00 & 0,00 & 5540,80 & 111 & 0,03 & 1,00 & 0,00 & 3742,98 \\
\hline 56 & 0,00 & 0,00 & 0,00 & 57324,16 & & & & & \\
\hline
\end{tabular}

Fonte: Elaborada pelos autores.

Desse modo, os especialistas comparam as previsões obtidas pelo método de Holt-Winter e verificaram que em alguns meses o método obtinha valores de previsão inferiores ao obtido pelo especialista. Desse modo, chegamos a Etapa (vi) "Obtenção da previsão final”. Os especialistas sugeriram o seguinte processo de previsão. Para cada produto são realizadas três 
previsões, sendo a primeira previsão ingênua para 2017 (cópia de 2016). A segunda previsão é obtida com a aplicação do método de Holt-Winter para os anos de 2013-2014-2015 e a terceira é a aplicação do mesmo método para os anos de 2014-2015-2016. Após obter as três previsões o critério de que o maior valor entre as três previsões geradas fosse escolhido como a previsão para cada mês.

Tabela 4: Dados da previsão de venda resultante do produto 1.

\begin{tabular}{|c|c|c|c|c|}
\hline Produto 1 & Vendas 2016 & $\mathbf{1 3 / 1 4 / 1 5}$ & $\mathbf{1 4 / 1 5 / 1 6}$ & Previsão \\
\hline Janeiro & 10 & 22 & 36 & 36 \\
\hline Fevereiro & 37 & 7 & 16 & 37 \\
\hline Março & 5 & 17 & 29 & 29 \\
\hline Abril & 16 & 11 & 16 & 16 \\
\hline Maio & 2 & 3 & 7 & 7 \\
\hline Junho & 20 & 2 & 9 & 20 \\
\hline Julho & 5 & 13 & 13 & 13 \\
\hline Agosto & 4 & 6 & 16 & 16 \\
\hline Setembro & 6 & 18 & 17 & 18 \\
\hline Outubro & 17 & 16 & 42 & 42 \\
\hline Novembro & 20 & 15 & 45 & 45 \\
\hline Dezembro & 19 & 5 & 29 & 29 \\
\hline
\end{tabular}

Fonte: Elaborada pelos autores.

A Tabela 4 exemplifica o processo de previsão da demanda para um produto. Na tabela, os meses foram atribuídos em cada linha e as colunas as previsões realizadas, seguindo a ordem já explicada anteriormente. Observe que no mês de Janeiro o método ingénuo prevê uma demanda de 10 unidade. O método de Holt-Winter aplicado nos anos de 2013/2014/2015 uma demanda de 22 unidade e o mesmo método para os anos de 2014/2015/2016 uma demanda de 36 unidade. Desse modo, a previsão acolhida pelos gestores é de 36 unidades (a maior entre as três previsões). Isso é feito mês a mês e para todos os 111 produtos selecionados.

$\mathrm{O}$ método foi aprovado pelos especialistas e implementado pela empresa. Cabe mencionar que o método é de fácil aplicação e utiliza recursos computacionais já existentes na empresa. Além disso, a participação dos especialistas nas decisões do método de previsão proposto facilitou com que a previsão final fosse aceita pela empresa.

A partir do momento em que são finalizadas as previsões de demanda, é possível obter a necessidade mínima de matéria-prima por meio da estrutura dos produtos e o processo de produção. Observe que, ao aplicar o método utilizado foi obtido apenas a demanda dos produtos finais. Como há interseção de produtos finais que faz uso do mesmo tipo de barra H2, há a necessidade de fazer levantamento da demanda da matéria-prima.

\subsection{Necessidade Bruta de Material e Dimensionamento do Lote de Compra}

Com base nas previsões já previamente calculadas e discutidas com os gestores escolhidos, gerou-se a entrada de dados para a decisão de compra da matéria-prima. Com isso, temos a Tabela 5 que apresenta quais são os H2's utilizados e seus respectivos produtos finais.

Cada barra de corte (produto final) possui uma barra chata (matéria-prima) de espessura e largura determinadas em milímetros. Cada barra chata de espessura e largura dada é denominada por H2. Assim, pode-se dizer que cada barra de corte está associada a uma H2 específico. Com isso foi trabalhado com a quantidade de 5 barras-chatas de aços distintos de modo que suas variações em largura, espessura e comprimento geram um novo código de H2, totalizando 28 H2's para a produção de 111 barras de corte.

Em outras palavras, alguns produtos tem a mesma matéria-prima em comum, com isso será feito o cálculo de todo o material necessário para o período de um mês. Como mencionado, a Tabela 5 identifica para cada barra-de-aço (H2) os itens que utilizam a barra. Desse modo, com a árvore do produto já estabelecida e a quantidade de itens a serem comprados já 
calculados, pode-se calcular a quantidade de barras de aço chato a serem cortadas para a fabricação das barras de corte.

Tabela 5: Tipos de barras H2.

\begin{tabular}{|c|c|c|c|c|c|c|c|c|c|c|c|c|c|c|c|c|}
\hline \multicolumn{17}{|c|}{$6,00 \mathrm{~mm} \times 19,00 \mathrm{~mm}$} \\
\hline H2001 & H2002 & \multicolumn{2}{|c|}{ H2003 } & \multicolumn{2}{|c|}{ H2004 } & \multicolumn{2}{|c|}{ H2005 } & \multicolumn{2}{|c|}{ H2006 } & \multicolumn{2}{|c|}{ H2007 } & H2008 & \multicolumn{2}{|c|}{ H2009 } & H2010 & H2011 \\
\hline \multirow[t]{9}{*}{ Barra 1} & \multirow{9}{*}{ Barra 2} & \multirow{9}{*}{\multicolumn{2}{|c|}{$\begin{array}{c}\text { Barra } 3 \\
\text { Barra } 4 \\
\text { Barra 5 } \\
\text { Barra } 6 \\
\text { Barra } 7 \\
\text { Barra } 8 \\
\text { Barra } 9 \\
\text { Barra } 10\end{array}$}} & \multirow{2}{*}{\multicolumn{2}{|c|}{$\begin{array}{l}\text { Barra } 11 \\
\text { Barra } 12\end{array}$}} & \multicolumn{2}{|c|}{ Barra 13} & \multicolumn{2}{|c|}{ Barra 22} & \multicolumn{2}{|c|}{ Barra 30} & Barra 34 & \multicolumn{2}{|c|}{ Barra 41} & Barra 43 & Barra 45 \\
\hline & & & & & & \multicolumn{2}{|c|}{ Barra 14} & \multicolumn{2}{|c|}{ Barra 23} & \multicolumn{2}{|c|}{ Barra 31} & Barra 35 & \multicolumn{2}{|c|}{ Barra 42} & Barra 44 & Barra 46 \\
\hline & & & & & & Barra & a 15 & \multicolumn{2}{|c|}{ Barra 24} & \multicolumn{2}{|c|}{ Barra 32} & Barra 36 & & & & Barra 47 \\
\hline & & & & & & \multicolumn{2}{|c|}{ Barra 16} & \multicolumn{2}{|c|}{ Barra 25} & \multicolumn{2}{|c|}{ Barra 33} & Barra 3 & & & & Barra 48 \\
\hline & & & & & & Barr & a 17 & Barra & 26 & & & Barra 3 & & & & Barra 49 \\
\hline & & & & & & Barr & a 18 & Barra & 27 & & & Barra 3 & & & & \\
\hline & & & & & & Barr & a 19 & Barra & 28 & & & Barra 4 & & & & \\
\hline & & & & & & Barr & 20 & Barra & 29 & & & & & & & \\
\hline & & & & & & Barra & a 21 & & & & & & & & & \\
\hline & &, 35 & $\mathrm{mm \times 1}$ & 9,05 & $\mathrm{~mm}$ & & & & & & & 6,35 & $\mathrm{~mm} \times 22$ & $22 n$ & $\mathrm{~mm}$ & \\
\hline & 2012 & & & $\mathrm{H} 2$ & 013 & & & 2014 & & 2015 & & 2016 & H201 & & H2018 & H2019 \\
\hline Barra 50 & Barra 5 & & Barra & & Barra & 65 & Bar & ra 70 & Bar & ra 75 & & irra 79 & Barra $\varepsilon$ & & Barra 83 & Barra 85 \\
\hline Barra 51 & Barra 5 & & Barra & & Barra & 66 & Bar & ra 71 & Bar & rra 76 & & irra 80 & Barra & & Barra 84 & \\
\hline Barra 52 & Barra 5 & & Barra & & Barra & 67 & Bar & ra 72 & Bar & ra 77 & & & & & & \\
\hline Barra 53 & Barra 5 & & Barra & & Barra & 68 & Bar & ra 73 & Bar & ra 78 & & & & & & \\
\hline Barra 54 & Barra 5 & & Barra & & Barra & 69 & Bar & ra 74 & & & & & & & & \\
\hline & & & 4,7 & $6 \mathrm{~m}$ & $\mathrm{nx} 19$, & $05 m n$ & & & & & & & 6,0 & $0 \mathrm{~mm}$ & $\mathrm{n} \times 25,00 \mathrm{~m}$ & \\
\hline H2020 & $\mathrm{H} 202$ & & $\mathrm{H} 2 \mathrm{C}$ & 22 & & 2023 & & H2024 & & $\mathrm{H} 2 \mathrm{O}$ & & & 2026 & & -2027 & H2028 \\
\hline Barra 86 & Barra & & Barr & 90 & Bar & ra 94 & & 3arra 9 & & Barra & 104 & Bar & ra 105 & & irra 108 & Barra 109 \\
\hline Barra 87 & Barra & & Barr & a 91 & Bar & ra 95 & & arra 10 & & & & Bar & ra 106 & & & Barra 110 \\
\hline & & & Bar & a 92 & Bar & ra 96 & & arra 10 & & & & Bar & ra 107 & & & Barra 111 \\
\hline & & & Barr & 93 & Bar & ra 97 & & arra 10 & & & & & & & & \\
\hline & & & & & Bar & ra 98 & & arra 10 & & & & & & & & \\
\hline
\end{tabular}

Fonte: Elaborada pelos autores.

Desse modo, após a previsão de vendas junto com a aplicação do cálculo das necessidades de materiais foi obtido o seguinte resultado dos itens que são produzidos diretamente do corte das barras de aço, nesse caso a lâmina e a meia lâmina de aço (observe a Figura 1 da estrutura do pedido). A quantidade de cada Lâmina e Meia-Lâmina é dada na Tabela 6. Observe, por exemplo, que na Lâmina 1 são necessárias 2302 unidades. Se multiplicarmos 2302 unidades pelo comprimento necessário da Barra $\mathrm{H} 2$ associada a essa lâmina será obtido a necessidade bruta da respectiva barra para a produção. Essa quantidade obtida será subestimada, uma vez que o corte de cada barra $\mathrm{H} 2$ irá gerar um desperdício.

O próximo passo é separar para cada $\mathrm{H} 2$ (tipo de barra de aço) os itens atribuídos segundo a Tabela 5. Para a quantidade de barras de aço chato, a serem cortadas de forma que não haja desperdício de matéria-prima é necessário determinar o processo de produção, neste caso, os padrões de corte dessas barras. Para determinar os padrões de cortes utilizados foi usado um modelo de corte de estoque unidimensional para que se pudesse fazer o arranjo correto dos cortes mensais. Os dados de entrada para o modelo matemático são obtidos a partir do plano mestre de produção de cada item. Para dimensão de cada barra de aço, para descrever os padrões de corte, foi considerada a dimensão comprada atualmente pela empresa.

$\mathrm{O}$ modelo de corte de estoque foi gerado para cada tipo de $\mathrm{H} 2$, já que cada $\mathrm{H} 2$ possui um comprimento específico. Com isso foi gerada a quantidade de aço chato a ser comprado a 
cada pedido para um giro de estoque de 20 dias. Para a resolução dos problemas foi usado um computador com o Windows 8, com software Microsoft Excel 2010, por meio da ferramenta solver. Com um processador i3 e 1GB de memória RAM.

Tabela 6: Necessidade de matéria-prima para um giro de estoque de 20 dias.

\begin{tabular}{|c|c|c|c|}
\hline \multicolumn{2}{|l|}{ Lâminas } & \multicolumn{2}{|l|}{ Meia Lâmina } \\
\hline Lâmina 1 & 2302 & Meia Lâmina 1 & 19 \\
\hline Lâmina 2 & 720 & Meia Lâmina 2 & 37 \\
\hline Lâmina 3 & 21609 & Meia Lâmina 3 & 205 \\
\hline Lâmina 4 & 26541 & Meia Lâmina 4 & 205 \\
\hline Lâmina 5 & 3768 & Meia Lâmina 5 & 194 \\
\hline Lâmina 6 & 926 & Meia Lâmina 6 & 194 \\
\hline Lâmina 7 & 6280 & Meia Lâmina 7 & 73 \\
\hline Lâmina 8 & 1016 & Meia Lâmina 8 & 81 \\
\hline Lâmina 9 & 15143 & Meia Lâmina 9 & 411 \\
\hline Lâmina 10 & 1535 & Meia Lâmina 10 & 129 \\
\hline Lâmina 11 & 60046 & Meia Lâmina 11 & 760 \\
\hline Lâmina 12 & 36204 & Meia Lâmina 12 & 135 \\
\hline Lâmina 13 & 799 & Meia Lâmina 13 & 23 \\
\hline Lâmina 14 & 383 & Meia Lâmina 14 & 23 \\
\hline Lâmina 15 & 329 & Meia Lâmina 15 & 64 \\
\hline Lâmina 16 & 829 & Meia Lâmina 16 & 64 \\
\hline Lâmina 17 & 144 & Meia Lâmina 17 & 186 \\
\hline Lâmina 18 & 430 & Meia Lâmina 18 & 186 \\
\hline Lâmina 19 & 4162 & Meia Lâmina 19 & 12 \\
\hline Lâmina 20 & 15163 & Meia Lâmina 20 & 16 \\
\hline Lâmina 21 & 12952 & Meia Lâmina 21 & 26 \\
\hline Lâmina 22 & 10421 & & \\
\hline Lâmina 23 & 7900 & & \\
\hline Lâmina 24 & 5592 & & \\
\hline
\end{tabular}

Fonte: Elaborada pelos autores.

\subsection{Resultados}

A partir do resultado de cada modelo, foi identificado a quantidade a ser comprada de cada barra de aço para ter um giro de estoque de 20 dias. Ou seja, o valor de barras definidos para esse giro de estoque, originou-se da média da previsão das barras anual, mas como a previsão foi feita mês a mês para um ano, houve a divisão dessa média por 30 dias para que se pudesse saber a demanda diária e posteriormente multiplicada por 20, para se ter o valor desejado. A Tabela 7 é fixa, pois a cada 20 dias tem-se essa demanda de barras de aço chato que deve ser consumida, haverá mudança apenas se o giro de estoque de 20 dias for modificado. Além disso, foi feita uma previsão da perda referente ao uso das barras, considerando o comprimento comprado pela empresa. Foi sugerido então que a empresa modificasse as dimensões das barras de aço chato, reduzindo em cada barra o valor equivalente a menor perda provocada entre os padrões de corte utilizados.

Os dados foram organizados na Tabela 7 na seguinte estrutura. A coluna Quantidade de barras diz respeito a previsão da quantidade de barras de aço chato trefilado que serão cortadas e perfuradas para a demanda de um giro de estoque de 20 dias para a produção das barras de corte.

A coluna Desperdício contém valores relativamente altos, pois foi considerada a igualdade na restrição de demanda do modelo. Notoriamente, essas barras podem ser mais bem aproveitadas pela empresa, mas também é de desejo da mesma, que não se tenha um grande 
estoque de matéria-prima com diversos comprimentos. Sabendo disso, foi feito um estudo para que se pudesse ter o melhor aproveitamento da matéria-prima dentro dos padrões da empresa.

A última coluna, Economia, apresenta os valores que ainda são desperdiçados quando é feito a redução do tamanho da barra do aço chato para a maior utilização dos planos de corte da solução ótima. Esses novos valores de desperdício foram obtidos quando foi alterado o tamanho do H2, para um tamanho um pouco menor que o original (redução equivalente a menor perda dos padrões de corte usados), as barras chatas originarias desse $\mathrm{H} 2$ já viriam com o tamanho exato da maior barra que ia ser utilizada.

Tabela 7: Resultados Computacionais.

\begin{tabular}{|l|r|r|r|}
\hline & $\begin{array}{c}\text { Quantidade } \\
\text { de barras }\end{array}$ & $\begin{array}{c}\text { Desperdício } \\
\text { em mm }\end{array}$ & $\begin{array}{c}\text { Economia } \\
\text { em mm }\end{array}$ \\
\hline H2001 & 31 & 2542,00 & 2480,00 \\
\hline H2002 & 6 & 1005,00 & 990,00 \\
\hline H2020 & 48 & 28147,00 & 12624,00 \\
\hline H2021 & 123 & 14726,40 & 7872,00 \\
\hline H2022 & 183 & 24163,40 & 3477,00 \\
\hline H2003 & 158 & 79448,40 & 8690,00 \\
\hline H2004 & 21 & 11577,20 & 966,00 \\
\hline H2006 & 54 & 9755,45 & 5129,60 \\
\hline H2007 & 86 & 17469,00 & 0,00 \\
\hline H2008 & 23 & 2649,00 & 460,00 \\
\hline H2028 & 34 & 8761,00 & 1190,00 \\
\hline H2023 & 5 & 164,00 & 150,00 \\
\hline H2026 & 178 & 35233,10 & 8900,00 \\
\hline H2024 & 10 & 338,40 & 35,00 \\
\hline H2027 & 228 & 60578,00 & 0,00 \\
\hline H2009 & 0 & 0,00 & 0,00 \\
\hline H2010 & 49 & 3189,10 & 1470,00 \\
\hline H2012 & 37 & 4223,00 & 2590,00 \\
\hline H2015 & 630 & 432316,50 & 22680,00 \\
\hline H2013 & 14 & 1037,00 & 225,00 \\
\hline H2014 & 354 & 142128,20 & 11894,40 \\
\hline H2016 & 165 & 16571,10 & 1848,00 \\
\hline H2011 & 13 & 1253,00 & 550,00 \\
\hline H2019 & 14 & 5638,60 & 1428,00 \\
\hline H2017 & 5 & 1017,00 & 775,00 \\
\hline H2018 & 27 & 7676,50 & 1485,00 \\
\hline H2025 & 31 & 25277,80 & 558,00 \\
\hline Total & 2.713 & $936.885,15$ & $98.467,00$ \\
\hline
\end{tabular}

Fonte: Elaborada pelos autores.

As colunas em que os desperdícios foram iguais a zero, significa que a produção dos itens utiliza a barra por completo e desse modo, não sendo possível diminuir o desperdício. $\mathrm{O}$ valor apresentado no desperdício está em milímetros, e essa redução de alguns milímetros em praticamente todas as barras de aço chato, apresentou uma economia de aproximadamente $10 \%$ de matéria-prima que deixa de desperdiçada e ser usada como sucata. Em termos contábeis, representa uma boa economia para a empresa a cada 20 dias, pois fazendo a diferença da segunda coluna com a terceira, e somando o resultado de cada economia temos 838.418,15 milímetros que resulta em 593 quilos. O quilograma do aço chato sendo comprado a $\mathrm{R} \$ 8,10$ temos uma economia de 4803,03 reais a cada 20 dias. 


\section{Conclusões}

O trabalho apresenta a viabilidade da aplicação de conceitos de Planejamento da Produção e Pesquisa Operacional, como métodos de previsão de demanda, MRP e problema de corte para estoque, em pequenas e grandes empresas. Pode-se dizer que havendo pessoas capacitadas para a aplicação e acompanhamento esses métodos utilizados são de grande valia para a melhoria de processos e redução de custos, sem a necessidade de grandes investimentos financeiros.

A utilização do Microsoft Excel é uma prática comum em indústrias, e a aplicação da ferramenta Solver pode contribuir para a manutenção das indústrias em um mercado tão competitivo, onde a melhoria de processos é uma busca constante.

O objetivo do trabalho foi o desenvolvimento de um método de dimensionamento do lote de compra da matéria prima da empresa. O método consiste em três etapas, sendo a primeira a previsão da demanda anual futura da empresa. O método quantitativo escolhido foi o de Amortecimento Exponencial Aditivo de Holt-Winter em conjunto com o método qualitativo, que foi o refinamento dos dados obtidos por meio da previsão quantitativa, com os gestores da empresa. Cabe mencionar que é necessária a análise dos gestores após a previsão, pois nesse momento está sendo tomada uma decisão estratégica da empresa.

Em seguida, na segunda etapa, foi feita a explosão dos itens para o cálculo da necessidade de cada item. Algumas matérias-primas como já vêm prontas para consumo, não precisam ser trabalhadas, o que não é o caso do aço chato utilizado na empresa, que necessita ser cortado, e estava apresentando muito desperdício. O método de cálculo de matéria prima faz uso de cálculos semelhantes ao MRP para determinar a demanda necessária dos itens, após a previsão de demanda. Por fim, na terceira etapa, por uso de um modelo de programação linear, são obtidas as quantidades das barras de aço de matéria-prima.

Cabe mencionar que, foi aplicado um método de pesquisa operacional de corte de barras para estoque, a fim de reduzir as perdas dessa matéria-prima. Embora o modelo matemático foi utilizado para obter uma estimativa da quantidade de objetos que seria necessária para a produção da demanda, os custos totais de produção são reduzidos, pois com uma prévia da combinação de corte de barras possível foi possível modificar o tamanho da barra de aço chato comprada para reduzir o desperdício, além de ter uma melhor estimativa do estoque necessário no período.

Além de possibilitar o melhor aproveitamento da matéria-prima e evitar que insumo de boa qualidade se torne sucata, irá diminuir o estoque de retalhos de aço chato $\mathrm{e}$ consequentemente a redução dos custos de produção e, aumento nos lucros. Após, foi estabelecido pelos gestores, um giro de estoque de todos os materiais para 20 dias e os valores de compra foram definidos para atender a previsão do giro de estoque.

Observa-se também que, o modelo de corte de estoque utilizado é aplicado a uma demanda agregada ao longo do mês, isso faz com que a quantidade de barras definidas pelo modelo possa ser subestimada. Além disso, o modelo não considera a produção de meio padrão de corte ou aproveitamentos de sobras, o que pode ser feito dentro da empresa. Essas considerações, embora relevantes no dia a dia da empresa, podem ser desconsideradas pois a decisão relacionada a esse trabalho é de longo prazo, ou de um ponto de vista estratégico.

Para Ragsdale (2009), no ambiente comercial e competitivo de hoje, é cada vez mais importante garantir que os recursos limitados de uma empresa sejam usados de maneira mais eficiente possível. O autor mostra ainda que, isso envolve determinar como alocar os recursos de maneira a maximizar os lucros ou minimizar custos. Para isso, pode-se dizer que a programação linear é uma ferramenta de otimização que se bem aplicada é eficaz e eficiente na distribuição de recursos da empresa.

Após aplicação de todo o método de dimensionamento do lote de compra de aço chato, foi feito uma proposta de que para cada barra $\mathrm{H} 2$, seu tamanho fosse reajustado subtraindo o menor desperdício dado pelos padrões de corte utilizados na solução, com essa nova proposta para a empresa, houve uma redução de cerca de $10 \%$ da matéria-prima utilizada. 
O estudo foi de grande valia, pois resolveu um problema de estoque e desperdício na empresa e a implantação dessa metodologia, o que proporcionou ao especialista uma melhor oportunidade de aprendizado com a aplicação prática de ferramentas da pesquisa operacional no meio industrial.

Ficou evidenciado neste artigo que os temas estudados são importantes e que demandam esforços no sentido de melhorar a qualidade do produto final e reduzir perdas e custos de produção. Como futuros trabalhos pode-se verificar a possibilidade de troca de algumas barras de mesma espessura e largura, mas com diferentes comprimentos entre os $\mathrm{H} 2$ 's para que o desperdício possa ser menor.

Cabe enfatizar mais uma vez que, embora os métodos de previsão e o modelo matemáticos sejam clássicos na literatura e não consideram peculiaridades do sistema produtivo da empresa, o fato de fazer uma previsão de demanda agregada e o objetivo de tomar uma decisão estratégica, faz com que as considerações desses métodos e modelos sejam suficientes para auxiliar as decisões dentro da empresa.

Ainda em relação a empresa, outros tipos de pesquisa-ação podem ser aplicadas na empresa, em especial as relacionadas a decisões táticas e operacionais. Em outras palavras, a aplicação de outros modelos matemáticos de corte de estoque existentes na literatura para auxiliar no planejamento da produção ao longo dos meses. Em especial, pode-se citar os modelos de corte de estoque que consideram sobras aproveitáveis.

\section{Referências}

Arenales, M., Armentano, V., Morabito, R e Yanasse, H. Pesquisa Operacional. $1^{\mathrm{a}}$ ed. Rio de Janeiro: Elsevier, 2007.

Ballou, R. H. Gerenciamento da Cadeia de Suprimentos: Planejamento, Organização e Logística Empresarial. $4^{\text {a }}$ ed. Porto Alegre: Bookman, 2001.

Caiado, J. Métodos de Previsão em Gestão - Com Aplicações em Excel. 2ª ed. Lisboa: Edições Sílabos, 2016.

Cherri, A. C. O problema de corte de estoque com reaproveitamento das sobras de material. Dissertação (Mestrado em Ciência da Computação e Matemática Computacional) - Instituto de Ciências Matemáticas e de Computação, Universidade de São Paulo, São Carlos-SP, 2006.

Corrêa, H. L. e Corrêa, C. A. Administração de Produção e Operações: Manufatura e Serviços: uma Abordagem Estratégica. São Paulo: Editora Atlas SA, 2012.

Davis, M. M., Chase, R. B. e Aquilano, N. J. Fundamentos da Administração da Produção. Porto Alegre: Bookman, 2001.

Gilmore, P. C. e Gomory, R. E. A linear programming approach to the cutting-stock problem. Operations Research, v. 9, n. 6, p. 848-859, 1961.

Heizer, J. H. e Render, B. Administração de Operações: Bens e Serviços. Rio de Janeiro: LTC, 2001.

Kamimura, Q. P., Paes, E. S. e Oliveira, E. A. A. Q. Inovação tecnológica: início de novos negócios em TI - estudo de caso numa empresa de bens de capital do Vale do Paraíba. Latin American Journal of Business Management, v. 3, n. 2, p. 174-187, 2012. 
Loeblein, L. C., Godoy, L. P., Taborda, L. W. e Oliveira, D. C. Aplicação da programação linear para minimização de perdas de aparas em indústria metal mecânica. Revista Gestão Industrial, v. 8, n. 4, p. 14-29, 2012.

Makridakis, S., Wheelwright, S. C. e Hyndman, R. J. Forecasting: Methods and Applications. $3^{\text {a }}$ ed. New York: John Wiley \& Sons, 1998.

Martins, P. G. e Larugeni, F. P. Administração da Produção. $2^{\mathrm{a}}$ ed. São Paulo: Saraiva, 2005.

Moreira, D. A. Administração da Produção e Operações. $2^{\mathrm{a}}$ ed. rev. e ampl. São Paulo: Cengage Learning, 2009.

Morettin, P. A. e Toloi, C. M. C. Análise de Séries Temporais. São Paulo, 2004.

Pellegrini, F. R. e Fogliatto, F. Estudo comparativo entre modelos de Winters e de Box-Jenkins para a previsão de demanda sazonal. Revista Produto \& Produção, v. 4, p. 72-85, 2000.

Poldi, K. C. e Arenales, M. N. O problema de corte de estoque unidimensional multiperíodo. Pesquisa Operacional, v. 30, n. 1, p. 153-174, 2010.

Ragsdale, C. T. Modelagem e Análise de Decisão. Ed. Revisada. São Paulo: Ed. Cengage Learning, 2009.

Salles-Neto, L. L., Araujo, S. e Golfeto, R. Um problema de corte de estoque multiobjetivo. Pesquisa Operacional para o Desenvolvimento, v. 6, n. 2, p. 183-201, 2014.

Samohyl, R. W., Souza, G. P. e Miranda, R. G. Métodos Simplificados de Previsão Empresarial. Rio de Janeiro: Editora Ciência Moderna, 2008.

Thiollent, M. Metodologia da Pesquisa-Ação. 15ª ed. São Paulo: Cortez Editora, 2007.

Wanke, P. e Julianelli, L. Previsão de Vendas. $1^{\text {a }}$ ed. São Paulo: Atlas, 2006.

Webby, R. e O'Connor, M. Judgemental and statistical time series forecasting: a review of the literature. International Journal of Forecasting, v. 12, n. 1, p. 91-118, 1996.

Werner, L. e Ribeiro, J. L. D. Modelo composto para prever demanda através da integração de previsões. Produção, v.16, n.3, p.493-509, 2006. 